\title{
REVISIÓN/REVIEW
}

\section{EL TWITTER DE ARISTÓTELES. UNA REVISIÓN DE LOS CONCEPTOS CLÁSICOS DE LA RETÓRICA CLÁSICA EN LA ACTUAL SOCIEDAD DIGITAL}

Francisco Cabezuelo Lorenzo': Universidad de Valladolid, Segovia. España. cabezuelo@hmca.uva.es Amelia González Sánchez: Universidad San Pablo CEU, Madrid. España. ameliags@gmail.com

\section{RESUMEN}

Este artículo se centra en el uso potencial de los principios clásicos de la Retórica revisada desde una perspectiva contemporánea. Hoy en día, un usuario de Internet sigue usando hoy, siglos más tarde, las estrategias comunicativas descritas por la disciplina retórica desde sus comienzos en la antigüedad griega, lo que significa o presupone la presencia de aspectos humanistas en la comunicación y al mismo tiempo le otorga una enorme creatividad. Podemos aplicar el modelo del ethos, logos y pathos a las redes sociales. Tales parámetros unidos a los recursos que ofertan las tecnologías emergentes configuran la fuerza persuasiva que caracteriza a las redes sociales.

PALABRAS CLAVE: Redes sociales - Aristóteles - Retórica - Twitter - Crisis Comunicación.

\footnotetext{
${ }^{1}$ Francisco Cabezuelo Lorenzo: Profesor ayudante doctor en la Facultad de Ciencias Sociales, Jurídicas y de la Comunicación del Campus de Segovia de la Universidad de Valladolid, España.

Correo: cabezuelo@hmca.uva.es
} 


\title{
ARISTOTLE'S TWITTER. REVISITING THE CLASSIC CONCEPTS OF THE CLASSICAL RHETORIC IN THE CURRENT DIGITAL SOCIETY
}

\begin{abstract}
This article focuses on the potential use of the classic principles of the Rhetoric from a contemporary approach. A current social media user continues using today, centuries later, the communicative strategies described by Aristotle in the Rhetoric, in the Old Greek times. It means and presupposes the presence of humanist aspects in the communication and, at the same time, it grants an enormous creativity to the digital tools. We can apply the ethos, logos and pathos model to the social media. Such parameters, joined with the resources that the emergent technologies offer, are the characteristics and the persuasive of the social media.
\end{abstract}

KEYWORDS: Social media - Aristotle - Rhetoric - Twitter - Crisis - Communication.

\section{INTRODUCCIÓN}

La crisis no es sólo un mal momento para la coyuntura económica y social en la que se encuentra un país como el nuestro en la actualidad. La crisis parece ser el estado actual de todas las cosas. Todo parece estar en crisis: la economía, las instituciones, la unidad del país, el sistema, los valores, la familia, de la sanidad, de la educación, de casi todos los negocios, y por supuesto de la industria de la comunicación, tanto la prensa como la publicidad. En tan sólo 0,26 segundos, Google (15/11/2013) nos ofrece más de 371 millones de entradas con la palabra "crisis", término que es igual en español, inglés o en su término original en latín, que a su vez viene del griego " ". Y esta cifra seguirá creciendo al ritmo que crecen los contenidos en la Red, es decir, de un modo imparable.

Más allá de la tan manida y recurrente frase, tan utilizada en estos días, que nos recuerda que en chino, "crisis" y "oportunidad" son dos significados de un mismo significante, este reflexión tiene la finalidad de analizar la crisis actual del sector de la comunicación tradicional (medios en papel) ante los nuevos retos digitales (Internet y las redes sociales) a la sombra de la lectura de los tres libros de la 'Retórica' de Aristóteles (384-322 antes de Cristo). Paradójicamente también las redes sociales se han convertido en una herramienta especialmente para la comunicación en tiempos de crisis (Cancelo Sanmartín \& Gadea Algave, 2013).

\section{LA CONSTRUCCIÓN DEL DISCURSO EN LOS MEDIOS DE COMUNICACIÓN}

La retórica como técnica se ha convertido en un arte menospreciado, olvidado y hasta repudiado. Pero, ¿es la construcción del discurso lo que más nos debe preocupar en estos tiempos de crisis? Sí, sin duda. Sí debe ser motivo de nuestra preocupación, de nuestro estudio y análisis, sobre todo en el nuevo contexto de crisis en el que es 
necesario revisar el actual 'status quo' de la esfera pública. Pero, además hay que ir más allá. La construcción del discurso es vital en la actual sociedad de masas. Sirvan como ejemplo temas de actualidad recientes como los conflictos de Gibraltar, el independentismo en Cataluña, entre otros, por poner un par de casos actuales sobre la mesa $^{2}$. Pero para hablar de estas cuestiones sería casi más interesante saltarse a autores clásicos y propios de la Teoría de la Comunicación como Harold Lasswell, Claude Shannon y Warren Weaver, Wilbur Schramm, Erving Goffman, Charles Peirce o Gerhard Maletzke, entre otros. Del mismo modo, cada día se usa más para el análisis de nuestras estructuras sociales, políticas y comunicativas la Teoría del Framing de George Lakoff ${ }^{3}$, convertido últimamente en el autor favorito de los politólogos de izquierda. De la misma manera, también es muy pertinente de la opinión del francés Roland Barthes, que estimaba en 1974 en su libro 'La antigua retórica' que "la retórica dejó de oponerse a la poética en favor de la noción trascendente que hoy designaríamos con el término Literatura" (Aristóteles, 1999: 12). No hay que olvidar la etimología conjunta de disciplinas como la Filosofía y la Filología.

Pero, la grandeza de las lecciones de Aristóteles es que su libro va más allá. Para empezar a hablar de Aristóteles, hay que decir, siguiendo a Walter D. Ross (1952), que la Retórica de Aristóteles es "una curiosa síntesis de crítica literaria y de lógica, de ética, de política y de jurisprudencia de segundo orden, mezcladas hábilmente por un hombre que conoce las debilidades del corazón humano y que sabe cómo jugar con ellas", tal y como se nos recuerda (pág. 8) en la Introducción de la edición de Gredos. Del mismo modo, también podemos interpretar los tres libros de la Retórica aristotélica como Charles Perelman (1952) que reivindicaba la Retórica como "una lógica de lo preferible", tal y como también se recoge (Aristóteles, 1999: 9) de la introducción.

Huyendo del relativismo, claramente criticado por Alasdair MacIntyre en 'Tras la virtud', pero fusionando eclécticamente los dos principios anteriormente citados podemos decir que el fondo y las formas no pueden estar separados. El hacer el bien y el hacerlo bien van juntos, van de la mano. Son una misma cosa. "Las cosas bien hechas, bien parecen", dice un refrán castellano. Por tanto, en el discurso público actual no podemos separar la verdad de la argumentación.

La retórica y la argumentación son omnipresentes en nuestra actual sociedad de masas, son los protagonistas del espacio público (Albadalejo, 1989). Están por todas

\footnotetext{
2 Tanto el tema de Gibraltar, durante los meses de julio y agosto de 2013, como la cadena humana por la Independencia, realizada el 11 de septiembre, con motivo de la Diada Catalana, son dos ejemplos de enfoque y encuadre diferente tanto en los medios de comunicación tradicionales como en los electrónicos. Dentro de España, se ve la brecha entre la prensa de Madrid y de Barcelona. La Razón y La Vanguardia, El País o el Periódico de Catalunya, por ejemplo, mantienen posiciones diferentes. Lo mismo ocurre con el contencioso de Gibraltar. Las posturas de la prensa de Madrid y Londres son diferentes.

${ }^{3}$ Sin duda alguna, el libro que mejor recoge estas posturas y que muchos asesores tanto del actual presidente americano Barack Obama, como el ex mandatario socialista español, José Luis Rodríguez Zapatero, han usado en 'No pienses en un elefante', en el que Lakoff aplica desde la Teoría de la Comunicación y la Teoría del Framing sus conocimientos al mundo de la Comunicación y la Retórica Política.
} 
partes. La metáfora, el recurso estilístico por antonomasia, es usada hasta la extenuación. Y en una sociedad tan hedonista como la nuestra no deja de aparecer en la publicidad. El ser humano, en actual sociedad de consumo, parece haber nacido para satisfacer sus placeres y para consumir. La publicidad nos retrata tan bien. Para ello, la industria publicitaria no deja de usar metáforas.

Aristóteles en los capítulos I-III del Libro I de la Retórica explica perfectamente los tres tipos de argumentos que se procuran en todo discurso (1356a): el ethos, que reside en el comportamiento y la autoridad del que habla; el logos, cuando se convence por el propio discurso; el pathos, que persuade por las emociones que despierta en el auditorio. Del mismo modo, Aristóteles nos recuerda que el ser humano no es un ser sólo racional, sino que obedece también a las emociones. Así que, para poder persuadir, un discurso debe apelar a tres dimensiones distintas en su audiencia: logos, ethos y pathos. Dicho en otras palabras, un argumento nos convence cuando sus premisas nos parecen racionales y convenientes (logos), cuando quien nos lo dice nos merece confianza (ethos) y cuando el argumento apela también a nuestras emociones (pathos).

\footnotetext{
"Ya los griegos, conscientes de la virtualidad del logos, comenzaron a desarrollar el arte de hablar bien y pusieron las bases de la elocuencia o retórica. Así, Platón cifró esta ciencia en ganarse la voluntad humana a través de la palabra; y su discípulo Aristóteles, figura central y referencia de la retórica, además de definir al ser humano por el lenguaje (el animal que habla), elaboró el método y las técnicas de la elocuencia. Desde entonces esta disciplina ha persistido sin dejar de renovarse según los condicionamientos del momento histórico". (Berlanga Fernández, 2012)
}

Esta es una buena base para comprender por qué las metáforas son un excelente artificio para la comunicación publicitaria en particular, pero para todo tipo de comunicación persuasiva en general. "Ver una cosa en términos de otra hace posible no sólo asegurar las proposiciones, sino establecer comparaciones tácticas que expanden nuestro juicio y nos producen el placer de la plasticidad que pueden tener los contenidos", afirma el profesor mexicano Alejandro Tapia en su blog (http://elarboldelaretorica.blogspot.com.es).

\section{LA RETÓRICA ARISTOTÉLICA EN LA SOCIEDAD DIGITAL}

La gran lección de Aristóteles es que los argumentos del retórico, del profesional de la comunicación, sólo pueden venir del "lógos mismo, esto es, del discurso" tal y como se afirma en la introducción del libro de Gredos (Aristóteles, 1999: 48-49). "En consecuencia, todos los elementos que no se refieren al asunto (pragma) de que se trata del discurso deben ser rechazados como no subsumibles en la sustancia de la argumentación" (1999: 49). Del mismo modo, "el ethos del orador admite, si bien sólo como elemento de apoyo para el caso de que se carezca de entinemas" (1999: 50), es decir, las ideas que ya están en la mente del receptor. Esta forma de actuar y sentir conforme al contexto y el entorno es una de las ideas más incómodas del provocador MacIntyre. 
Así, por tanto, la gran pregunta a la que pretendo responder con este trabajo y esta reflexión es saber cómo podemos aplicar las ideas de nuestro querido Aristóteles a la actual sociedad digital, al mundo que vivimos hoy en día. La Retórica es una disciplina antigua que data del siglo $\mathrm{V}$ antes de Cristo, pero que como ya hemos visto está muy presente en nuestras vidas a través de los medios de comunicación, tradicionalmente, de la prensa, la radio, el cine y la televisión.

La profesora Inmaculada Berlanga Fernández (2012) de la Universidad Internacional de La Rioja (UNIR) resume de este modo los principales conceptos necesarios para comprender los fundamentos de la Retórica clásica aplicados a los actuales tiempos de crisis en el mundo de la comunicación social:

La inventio, o invenio, del latín invenire que a su vez procede del griego $\quad \hat{v} \quad$ (hallazgo), es la investigación, el estudio y establecimiento de los contenidos del discurso. Estos contenidos los encuentra el orador en su memoria, fruto de ideas propias o heredadas de lugares comunes de la sociedad en general. La dispositio, traducción del término griego $\dot{\alpha}$ (disposición) consiste en organizar los elementos de la inventio en una estructura que habitualmente consta de tres partes: un exordium o parte inicial que tiene por objeto captar la atención, el interés y simpatía del oyente (captatio benevolentiae) e indicarle la estructuración del discurso; una parte media con narratio o exposición del asunto y tesis del orador y argumentatio o razones que sustentan dicha tesis; finalmente, una peroratio o recapitulación de los puntos fuertes expuestos, con apelaciones al auditorio para inclinar su voluntad hacia una impresión final favorable. La elocutio sería el modo de decir o expresar el contenido de la inventio una vez estructurados; el estilo, en una palabra, que se pone de manifiesto a través de tres cualidades: la puritas es la corrección gramatical en la expresión lingüística o semántica y en la sintaxis; la perspicuitas es el grado de comprensibilidad del discurso, que se opone a la obscuritas, y el ornatus o embellecimiento del discurso con el uso de las distintas figuras literarias. La memoria es el recordatorio del discurso, bien por memoria innata, bien por procedimientos mnemotécnicos. La actio, o pronuntiatio, se ocupa de la declamación del discurso, prestando atención a la modulación de la voz y de los gestos, que deben estar en consonancia con el contenido del mismo.

Pero, ¿qué pasa con Internet? Internet es hoy el "medio-multi-media". Es el medio por antonomasia. El fenómeno de la convergencia mediática ha hecho que todos los viejos medios tradicionales estén hoy unidos en uno: Internet. Además, Internet, nacido en el siglo $X X$, tiene ya sus hijos adultos en el siglo XXI: las redes sociales.

Sin duda alguna, la Retórica nos sirve y ayuda a explicar el intrincado concepto de Internet, a facilitar su práctica cotidiana y a su construcción de una forma ordenada y sistemática. Todo el concepto de Internet está basado en la gran metáfora. Es la metáfora de la tela de araña, de la gran red de redes. Internet consiste en millones de puntos de comunicación esparcidos por la faz del planeta conectados por una intrincada red tejida de cables que ni la mitológica Aracne hubiera sido capaz de hilar mejor en sus mejores sueños. La red es hoy global. Llega a todo el mundo. Tal y como sucedía en la Grecia clásica con el ágora pública que impedía el concurso a mujeres y esclavos, también en estos "espacios de libertad" que plantean herramientas como Facebook o Twitter existe una restricción personificada en la brecha digital ${ }^{4}$.

${ }^{4}$ Si bien es cierto que no podemos olvidar el fenómeno de la brecha digital que hace que a la gente con menos recursos Internet no les llegue y no tengan los beneficios que ello conlleva. El único impedimento para poder acceder a Internet es de carácter tecnológico y técnico. Se necesita, como 
Para algunos autores, como el profesor Roberto Gamonal, de la Universidad Complutense de Madrid (UCM), con Internet nos hemos "helenizado". "La cultura occidental, basada en los principios filosóficos de la Antigüedad Clásica, ha sufrido innumerables cambios con la llegada de este medio de comunicación social", afirma.

La Retórica, en su acepción clásica, es el arte del discurso o de la palabra eficaz y su desarrollo como disciplina se fraguó en el ágora: la plaza pública que constituía el centro neurálgico de la vida pública, política, comercial y cultural de la polis griega. Dentro del ágora, se encontraba el "bouleuterion", un recinto donde se celebraba la asamblea y se discutían las cuestiones políticas. Este espacio tenía forma de teatro para poder escuchar mejor al orador, para verlo y que todos fueran vistos.

En la actualidad no existe un espacio físico como el ágora griega, a excepción de los medios de comunicación, medios que se han volcado en Internet, al darse cuenta de su potencial. Si al inicio de este trabajo hablábamos de crisis institucional, se puede decir que esta se agrava día a día. Se han separado los asuntos políticos de la vida cotidiana. Para algunos autores, nuestras instituciones políticas actuales no son tan accesibles para el ciudadano actual como para el ciudadano griego. Ahora se necesita de la ostentación de un cargo público elegido mediante el sistema de votación para participar de una forma directa en los asuntos públicos. No hay que olvidar, siguiendo también a Aristóteles, que el ser humano es un "animal político" (zoon politikon) y "un animal retórico" (zoon rhtorikon), con una inclinación natural al uso de la palabra para el debate de los asuntos políticos, nos recuerda el profesor Gamonal.

Lo más parecido al ágora en la actualidad es Internet, con la salvedad de que la Red no es un espacio físico, por lo que incluso se puede afirmar que Internet es hoy la utopía del ágora en pleno siglo XXI. Así, para muchos analistas, tanto la web como las redes sociales se han convertido hoy en un ágora virtual, en un espacio público inmaterial al que cualquier persona tiene acceso y en el que también se desarrollan actividades económicas, políticas y culturas como en la antigua ágora griega. De hecho, las redes sociales se usan como termómetro para medir la temperatura de la opinión pública. Las tertulias de actualidad política de la televisión de TVE, La Sexta, 13 TV o Intereconomía TV están constantemente haciendo referencia a la opinión de sus telespectadores en Twitter, por ejemplo.

\section{LAS CATEGORÍAS DE ARISTÓTELES ANTE LAS REDES SOCIALES}

La televisión tardó trece años en conseguir cien millones de usuarios, Internet empleó cuatro y el iPod de Apple necesitó tres años. Facebook llegó al centenar de millones de usuarios en apenas nueve meses (Caerols-Mateo et alt, 2013). Además, España es uno de los países con mayor consumo de redes sociales, y dentro de éstas, Facebook destaca dominando el ecosistema. Instagram, que fue comprada por Facebook en abril de 2012 por una cantidad cercana a los 1.000 millones dólares, una aplicación cuya

mínimo, un teléfono o un ordenador, una conexión y unos conocimientos básicos para navegar. Aunque esta tecnología está cada vez más al alcance de todos, sigue siendo imposible para personas con pocos recursos económicos como ocurre en tantos lugares del Tercer Mundo o en los grupos más desfavorecidos de nuestras sociedades occidentales. 
virtud principal es la capacidad de interacción entre marca y usuario a través de la fotografía, es uno de los mejores ejemplos del éxito de las nuevas redes sociales del mundo digital.

Se puede afirmar por tanto Internet y las redes sociales son espacios públicos y abiertos, pero también tienen sus restricciones. Hay que recordar que en la antigua Grecia, también las había. Por ejemplo, las mujeres no podíamos participar en los asuntos políticos los hombres. Las mujeres, los esclavos y los extranjeros estaban excluidos y marginados.

Afortunadamente, en la Red no existen este tipo de exclusiones porque puede acceder a ella cualquier persona sin distinción de credo, nivel socioeconómico, raza, condición sexual, o posicionamiento político. Cualquier persona puede exponer, publicar, opinar y decir lo que quiera sin trabas ni censura. Esta libertad sin límites da lugar a otros problemas como la falta de veracidad, la piratería, la mentira, la violación de los derechos de autor y de otros tantos derechos, incluso más importantes.

De todos modos, incluso con estos problemas y trabas, Internet ha superado con creces al ágora griega en cuanto a libertad de acceso y difusión de conocimiento. Pero, ¿quién ha diseñado la Red? ¿Cómo se ha creado? ¿A qué se parece? La profesora Inmaculada Berlanga, experta en Retórica y Nuevos Medios, considera necesario hablar de un nuevo "rétor" como actor de este escenario ante el que nos encontramos hoy. "El rétor, en este caso la persona -o el equipo- que ha diseñado la Red, ha realizado su "inventio" o establecimiento de los contenidos extrayéndolos de los lugares comunes que los usuarios y él mismo, por su formación visual, tienen en su memoria, afirma Berlanga (2012), que estima que gracias a esto, se asocian conceptos a unos determinados iconos e imágenes.

Por tanto, podemos preguntarnos cómo podemos aplicar las ideas de la Retórica aristotélica al actual mundo digital. ¿Siguen siendo útiles las ideas de Aristóteles para entender la comunicación hoy en día? ¿Y si Aristóteles viera hoy Facebook? Algunos autores se han preguntado ya qué opinaría McLuhan de un iPhone o un iPad (Viñas Limonchi \& Cabezuelo Lorenzo, 2011). Pero, ¿qué opinaría Aristóteles de las redes sociales? Probablemente haría el mismo análisis de la comunicación persuasiva que hizo varios siglos antes del nacimiento de Jesucristo. Hoy en día se puede afirmar que la presencia de la Retórica en la comunicación generada en las redes sociales online es real y los modelos aristotélicos siguen siendo válidos.

Un usuario de las redes sociales sigue usando hoy, siglos más tarde, las estrategias comunicativas descritas por la disciplina retórica desde sus comienzos en la antigüedad griega, lo que significa o presupone la presencia de aspectos humanistas en la comunicación y al mismo tiempo le otorga una enorme creatividad. Podemos aplicar el modelo del ethos, logos y pathos a las redes sociales. Tales parámetros unidos a los recursos que ofertan las tecnologías emergentes configuran la fuerza persuasiva que caracteriza a estas redes sociales. 
Pero, volviendo al principio de este trabajo. ¿Cómo podemos aplicar los principios aristotélicos al fenómeno, por ejemplo, de las redes sociales? La falta de sólidos fundamentos basados en los orígenes clásicos ha hecho que quizás Internet y las redes sociales no sean un fenómeno que se ha explicado correctamente. Para autores como Inmaculada Berlanga o Francisco García-García, "uno de los agujeros negros de la investigación en comunicación tiene que ver con una carencia de profundización en los orígenes clásicos de nuestros estudios, de sus objetos y de los acercamientos a estos". Así, por tanto, es especialmente útil y relevante aplicar el estudio de los procesos comunicativos en Internet, en concreto a través de las redes sociales, bajo el prisma de la Retórica aristotélica. Es decir, hay que entender y explicar Facebook, Twitter o Tuenti, desde el uso de las estrategias de persuasión del ethos, pathos y logos. Tales parámetros unidos a los recursos que ofertan las tecnologías emergentes otorgan una enorme creatividad y aportan aspectos humanistas a la comunicación en red, claves de la fuerza persuasiva que caracteriza a estas plataformas online.

De este modo, Inmaculada Berlanga, Francisco García-García y Juan Salvador Victoria Mas hablan del usuario de redes como el nuevo "rétor" del siglo XXI. Los citados autores consideran que el usuario de estas plataformas utiliza las estrategias comunicativas descritas por la disciplina retórica desde sus comienzos en la antigüedad grecolatina. Lo demuestran con el análisis de contenidos de las conversaciones generadas en los muros de Facebook. Este análisis permite entrelazar la Retórica y nuestro presente comunicativo mediado por la emergencia de las redes. Por tanto, hay que afirmar que es posible recuperar unos parámetros que devuelvan el pensamiento profundo y crítico en favor de una comunicación digital, pero más humana, basado en los fundamentos de Aristóteles.

En los últimos tiempos hemos consolidado Internet como esa gran ágora griega o foro romano en el que en pocos años se ha consolidado una sociedad de "todocomunicación" ${ }^{\prime}$, en la que la información circula prioritariamente a través de redes sociales, con millones de personas conectadas en todo el mundo. Siguiendo la metáfora del ágora y del foro, bien podríamos hablar incluso de Internet como "mentidero" al más puro estilo de los mentideros del Siglo de Oro español.

Así, Inmaculada Berlanga considera que Facebook cumple con las partes del discurso, la estrategia expresiva y el uso de las figuras retóricas que ya ideó Aristóteles en la Antigua Grecia. Así, en el terreno de las estrategias, esta autora considera que la ligada al pathos (sentimientos, emociones) domina sobre el ethos (hábitos, costumbres) y el logos (dialéctica, argumentos). Es decir, que un comentario en una red social como Facebook o Twitter que apele al sentimiento será más efectivo que otro que se base únicamente en un discurso racional, motivo que explica el uso afectivo, sentimental y lúdico de Facebook, frente a una finalidad laboral, administrativa o logística para el sector productivo. Es más, está considerada una herramienta ante todo de ocio, como demuestran Soria-Ibáñez (2013) y Hernández-Pérez (2012).

\footnotetext{
5 “Todo-comunicación” es el término usado por Inmaculada Berlanga, Francisco García García y Juan Salvador Victoria Mas.
} 


\section{DISCUSIÓN}

Las redes se han impuesto formando ya parte de nuestra vida personal, social y laboral. Hay que recordar que no sólo usamos las redes como Twitter para temas personales, se usan sobre todo por parte de muchos profesionales como herramientas de reputación profesional para obtener visibilidad en la red y aumentar el reconocimiento o prestigio o tener más clientes y seguidores, y por tanto, más oportunidades de negocio.

Al acercarnos al discurso de las redes es fácil apreciar los profundos cambios epistemológicos producidos en el campo de las Ciencias de la Comunicación. El fenómeno comunicativo precisa ser repensado desde una teoría ligada al campo digital pero con una perspectiva humanista. En este proceso de cambio siguen reconociéndose claramente los elementos y estrategias de la Retórica clásica pero ahora reforzados por las posibilidades que ofertan las nuevas tecnologías de la información y de la comunicación.

Gracias a Internet y a las redes sociales, hoy en día, el contacto entre usuarios separados por miles de kilómetros se realiza en cuestión de segundos. La cantidad de información y datos conocimientos generados multiplica todo el conocimiento difundido por los griegos. De hecho, algunos autores estiman que Internet ha conseguido "colonizar" el mundo entero de una forma mucho más rápida añadiendo a la transmisión oral, la palabras escrita, la imagen, el sonido, el vídeo y la animación. Es el fenómeno de la convergencia mediática. Con el mítico Alejandro Magno llegó el ocaso, el fin del esplendor de la filosofía griega y se terminó con la autonomía de las ciudades griegas (polis).

Hoy, sin embargo, las batallas tienen lugar en la red, como nos han enseñado escándalos como Wikileaks. Las conexiones a través de la red de Internet han conseguido traspasar las fronteras del tiempo y el espacio. Pero, precisamente es el exceso de información es la mayor crítica que se le hace a Internet. Se vive el fenómeno de la falta de credibilidad de las fuentes online, de las estafas y mentiras en la red, de la piratería. Incluso para muchos esta saturación de información por todas partes nos produce una "infoxicación", conforme al término inventado por Enrique Dans. La abundancia de contenidos poco fiables e incluso ilegales desprestigia a Internet, que sin embargo desarrolla una excelente labor divulgadora muy útil para todos.

Del mismo modo en que algunos en los momentos críticos de la Retórica, dijeron que ésta no es ni más ni menos que una forma artificiosa y hueca de adornar el discurso, por desgracia, hoy también Internet está adquiriendo connotaciones negativas por su mal uso o abuso, pero eso sería juzgar el todo por una parte.

No podemos negar que Internet es el gran avance por excelencia de los últimos tiempos. Su uso incorrecto no exime su gran potencial. Internet responde hoy a las preguntas que Aristóteles ya formulara varios siglos antes de Cristo. Aristóteles elaboró la primera gran teoría de la comunicación dentro de Historia de la 
Comunicación Social y su modelo sigue siendo válido y útil hoy en día, en pleno siglo XXI.

\section{REFERENCIAS}

Albaladejo, T. (1989). Retórica. Editorial Síntesis, Madrid.

Aristóteles (1999). Retórica. Con introducción, traducción y notas de Quintín Racionero. Segunda edición. Biblioteca Clásica Gredos. Editorial Gredos, Madrid.

Barthes, R. (1974). La antigua retórica. Editorial Tiempo Contemporáneo, Buenos Aires.

Berlanga-Fernández, I. (2012): Nuevas ágoras de la democracia posmoderna: las redes sociales online/The New Agores of Postmodern Democracy: Online Social Networks. Telos: Cuadernos de Comunicación e Innovación. ISSN 0213-084X, Núm. 92, Págs. 118-126.

Berlanga-Fernández, I., García-García, F. \& Victoria Mas, J. S. (2013). Ethos, logos y pathos en Facebook. El usuario de redes: nuevo "rétor" del siglo XXI. Revista Comunicar. Universidad de Huelva. DOI: http://dx.doi.org/10.3916/C41-2013-12

Caerols-Mateo, R., Tapia-Frade, A. Carretero-Soto, A. (2013). Instagram, la imagen como soporte del discurso comunicativo participado. Revista de Comunicación Vivat Academia. Septiembre de 2013. Año XV. Núm. 124. Págs. 68-78.

Cancelo-Sanmartín, M. \& Gadea-Algave, G. (2013). Empoderamiento de las redes sociales en las crisis institucionales. Revista de Comunicación Vivat Academia. Septiembre de 2013. Año XV. Núm. 124. Págs. 21-33.

Gamonal-Arroyo, R. (2004). Cyber-retórica: La retórica en Internet. Revista Icono 14. Núm. 3. ISSN 1697-8293. Madrid, España.

García-García, F. (2005). Una aproximación a la historia de la Retórica. Revista Icono 14. ISSN 1697-8293. 
Hernández-Pérez, M. (2012). De perfiles y personajes: evolución de la representación del usuario en las redes sociales y los juegos de rol. Revista de la SEECI, ISSN 1576-3420, Núm. 28, Año XV. Págs. 3048.

Lakoff, G. (2007). No pienses en un elefante. Foro UCM-Editorial Complutense, Madrid.

MacIntyre, A. (2004). Tras la virtud. Biblioteca de Bolsillo. Editorial Crítica, Barcelona, 2004.

Soria-Ibáñez, M ${ }^{\mathrm{a}}$ M. (2013). Influencia del uso de las redes sociales en estudiantes hispanohablantes en el tiempo de ocio y estudio. Revista de la SEECI, ISSN 1576-3420, Núm. 31, Año XVI. Págs. 34-51.

Viñas-Limonchi, M. \& Cabezuelo-Lorenzo, F. (2011). Si McLuhan tuviera un iPad: Nuevos paradigmas comunicativos extraídos de los inventos de Apple. Espéculo. Revista de Estudios Literarios. ISSN 1139-3637, Núm. 47.

\section{Francisco Cabezuelo Lorenzo}

Es profesor en el área de Comunicación Audiovisual y Publicidad (CAVP) en la Facultad de Ciencias Sociales, Jurídicas y de la Comunicación de la Universidad de Valladolid, en el Campus de Segovia. Es doctor europeo en Tecnologías, Estructuras y Tratamientos de la Información por la Universidad Complutense de Madrid (UCM) y Licenciado en Periodismo (UCM) y Licenciado en Publicidad y Relaciones Públicas (UCJC).

\section{Amelia González Sánchez}

En la actualidad realiza un Doctorado en Análisis de la Sociedad de la Información y Nuevas Formas de Comunicación en la Facultad de Humanidades y Ciencias de la Comunicación de la Universidad San Pablo CEU de Madrid. Es Licenciada en Ciencias Económicas por la Universidad Carlos III de Madrid. Cuenta con una amplia experiencia en el mundo de la empresa privada, concretamente en las áreas de marketing y comunicación empresarial, actividad que compagina con la docencia en prestigiosas escuelas de negocio de nuestro país. 